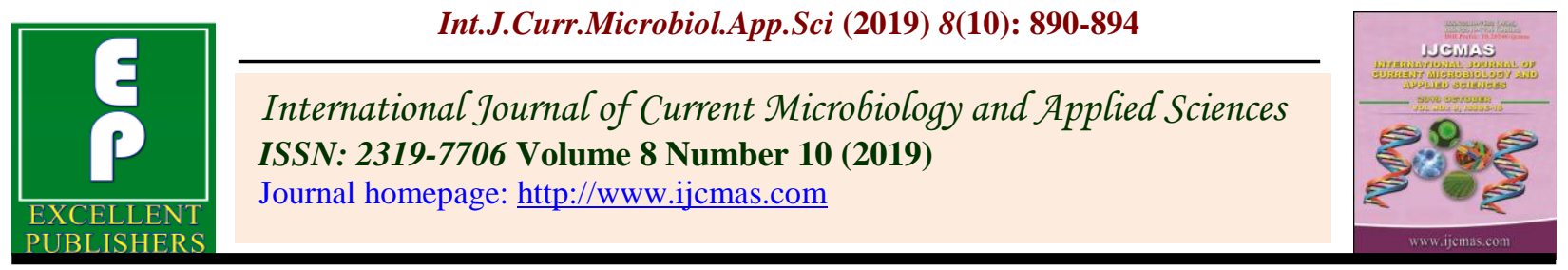

Original Research Article

https://doi.org/10.20546/ijcmas.2019.810.103

\title{
Study on Adoption of Recommended Cultivation Practices in Little Millet (Panicum millare) among Hilly Tribe Farmers in Jawadhu Hills of Tiruvannamalai District, India
}

\author{
S. Vasanthapriya ${ }^{1 *}$ and M. Asokhan ${ }^{2}$ \\ ${ }^{1}$ Department of Agricultural Extension and Rural Sociology, TNAU, Coimbatore, India \\ ${ }^{2}$ Deputy Registrar (Affiliation), TNAU, Coimbatore, India \\ *Corresponding author
}

Keywords

Millet (Panicum millare), Adoption, Hilly tribe farmers, Jawadhu hills

Article Info

Accepted:

10 September 2019

Available Online:

10 October 2019

\section{A B S T R A C T}

The study on adoption of recommended cultivation practices in little millet (Panicum millare) among hilly tribe farmers in Jawadhu hills of Tiruvannamalai district was selected purposively, since it is one among the districts where the little millet (Panicum millare) is cultivated in larger area by the hilly tribe farmers. The Ex-post facto research design is adopted for this study. The study was confined with seven villages namely Kovilur, Nammiyampattu, Kanamali, Veerappanur, Melsilambai, Palamarathur and Kuttakarai from Jamunamarathur (Jawadhu hills) block of Tiruvannamalai district. The sample size of 240 respondents was selected from these villages by proportionate random sampling method. The respondents were interviewed personally by a well-structured and pre-tested interview schedule. The statistical tools of mean, standard deviation, cumulative frequency and percentage analysis were used to analyze the collected data. In this context the overall adoption, technology-wise adoption of little millet cultivation practices among tribal farmers were discussed.

\section{Introduction}

Two main groups of millets are major millets (sorghum and pearl millet) and small millets based on the grain size. Both major and small millets have traditionally been the main components of the food basket of the poor people in India. Millets are the most important crops in the semi-arid tropics of Asia and Africa (especially in India, Nigeria, and Niger), with 97 per cent of millet production in developing countries.

The crop is favoured due to its productivity and short growing season under dry, high temperature conditions. (http://www.fao.org/) 
Little millet or Samai is widely cultivated as cereal across India, Nepal and Western Burma. Presently, it is grown throughout India in more than half a million hectare with major area being in the states of Karnataka, Andhra Pradesh, Tamil Nadu, Orissa, Bihar, Maharashtra and Madhya Pradesh. Little millet (Samai) is grown in Dharmapuri, Salem, Erode, Coimbatore, Madurai and Vellore districts of Tamil Nadu. It is preferred in extreme soil and climatic conditions of tribal agriculture. The average grain yield is 400-600 kg/ha (DHAN foundation, 2012).

Being mostly rain fed kharif crops, millets will have to at least compete and compare reasonably well with oil seeds, pulses and other newer crops in terms of monetary returns. In such a scenario millets often lag behind because of lower total monetary returns which is due to multiple factors such as (1) Lower productivity (2) Increasing cost of production (3) Lack of remunerative market and (4) stagnant demand. Unless this complex issue is addressed by appropriate policy interventions; without creating a level playing ground there is little hope for mainstreaming millets production and consumption (Directorate of millets Development, 2010).

The Department of Millets, Centre for Plant Breeding and Genetics, Tamil Nadu Agricultural University, Coimbatore has implemented a project named Upscaling popularization of little millet in Jawadhu hills of Thiruvannamalai district, Tamil Nadu for enhancing the livelihood of tribal farmers on June 2011 for 3 years with Rs. 3.21 million. The Phase I project on millets has recorded an 82.30 per cent increase in little millet yield, simply through using quality improved seeds and following a scientifically validated methods for millet cultivation. However, as it was piloted in only 100 hectares, in comparison to the total area of 4880 hectares under little millet cultivation, there is immense scope of upscaling this project and reaching out to approximately 3500 tribal families in Jawadhu hills. For these families, little millet cultivation can be developed into a highlyprofitable venture, yielding a net income of Rs. 15,000 to Rs. 20000 per hectare. In Phase II, the aim is to saturate the area with little millet cultivation, which being highly nutritious and multi-purpose in nature, will be able to successfully address food, nutritional, fodder and feed needs of tribal farmers in this region. Being a lucrative and beneficial livelihood option, the project will be developed into a model for the Department of Agriculture, Tamil Nadu, for upscaling it to all millet growing districts in Tamil Nadu as well as bringing little millet back on the state agriculture agenda. (http://www.srtt.org/)

With this background, the study on adoption of recommended cultivation practices in little millet (Panicum millare) among hilly tribe farmers in Jawadhu hills of Tiruvannamalai district was taken in to consideration.

\section{Materials and Methods}

Ex-post facto research design is adopted for the study. Tiruvannamalai district in Tamil Nadu was purposively selected because it is one of the districts in Tamil Nadu where the area under little millet cultivation is high. Jamuna marathur (Jawadhu hills) block was selected, since it has maximum number of tribal farmers cultivating little millet in Tiruvannamalai district. Seven villages namely Kovilur, Nammiyampattu, Kanamalai, Veerappanur, Melsilambadi, Palamarathru and Kuttakarai were selected for the study where the percentage of tribal population is high. The lists of little millet cultivating hilly tribal farmers were obtained from the records of the Village Administrative Officers. Proportionate random sampling procedure was employed in selecting 240 respondents from the selected seven villages. A sample of 65 member form 
Kovilur, 44 members from Nammiyampattu, each 35 members form Kanamalai and Veerappanur, 23 members from Melsilambai and for remaining 38 members, each 19 members selected from Palamarathur and Kuttakarai. The data were collected using a pre-tested interview schedule were subjected to statistical test to get the meaningful interpretations.

\section{Results and Discussion}

\section{Adoption of recommended cultivation practices in little millet}

The overall and recommended cultivation practices wise adoption of little millet crop get enlightened in this topic.

\section{Overall adoption level on recommended} cultivation practices in little millet

The information was collected for studying the overall adoption level of the respondents on the recommended cultivation practices on little millet were analysed and the results are presented in Table 1.

From Table 1, it could be observed that more than two-third $(63.70 \%)$ of the respondents had medium level of adoption of recommended little millet cultivation practices. Nearly one-fifth $(19.20 \%)$ of the respondents had low level of adoption followed by less than one-fifth $(17.10 \%)$ of the respondents had high level of adoption of recommended little millet cultivation practices.

The medium and high levels of adoption of recommended little millet cultivation practices by the respondents influenced majorly with agriculture and agricultural labour as the occupational status exist among the tribal farmers. Also the medium and high level of adoption get inclined with the medium level of farming experience, material possession, innovativeness and information seeking behaviour of the tribal respondents. Here, the low level of adoption was occurred due to conservative nature of the respondents made them to omit the recent technologies given by the state department of agriculture.

The results are in line with the findings of Vasanthapriya (2015).

\section{Technology-wise adoption of recommended cultivation practices in little millet}

To study the adoption level of the respondents 12 recommended cultivation practices in little millet were considered and the findings on the adoption level of the respondents on the selected practices are detailed in the Table 2.

From Table 2, it could be observed that among the twelve recommended technologies, more than three-fourth $(82.50 \%)$ of the respondents had adopted the variety which is recommended for that area. Cent per cent of the respondents followed the recommended season for cultivating little millet in hilly area. Majority (99.60\%) of the respondents had adopted field preparation practices.

Seeing the seed rate more than one-fifth $(22.50 \%)$ of the respondents had adopted the recommended quantity. In sowing, half $(50.80 \%)$ of the respondents found to get adopt the recommended practice. With reference to the seed treatment $(0.40 \%)$ and spacing $(0.80 \%)$ the adoption level were found negligible.

Meagre $(6.70 \%)$ level of adoption was found with nutrient management. About 97.50 per cent of the respondents had adopted the recommended weed management practices at the study area. 
Table.1 Distribution of respondents based on the overall adoption level on recommended cultivation practices in little millet

\begin{tabular}{|c|c|c|c|}
\hline S. No. & Category & Number & Per cent \\
\hline 1. & Low & 46 & 19.20 \\
\hline 2. & Medium & 153 & 63.70 \\
\hline 3. & High & 41 & 17.10 \\
\hline & Total & $\mathbf{2 4 0}$ & $\mathbf{1 0 0 . 0 0}$ \\
\hline
\end{tabular}

Table.2 Distribution of respondents according to their adoption of recommended little millet cultivation practices

\begin{tabular}{|c|c|c|c|}
\hline S. No. & Recommended practices & Number $^{*}$ & Per cent \\
\hline $\mathbf{1 .}$ & Variety & 198 & 82.50 \\
\hline $\mathbf{2 .}$ & Season & 240 & 100.00 \\
\hline $\mathbf{3 .}$ & Field preparation & 239 & 99.60 \\
\hline $\mathbf{4 .}$ & Seed rate & 54 & 22.50 \\
\hline $\mathbf{5 .}$ & Sowing & 122 & 50.80 \\
\hline $\mathbf{6 .}$ & Seed treatment & 1 & 0.40 \\
\hline $\mathbf{7 .}$ & Spacing & 2 & 0.80 \\
\hline $\mathbf{8 .}$ & Nutrient management & 16 & 6.70 \\
\hline $\mathbf{9 .}$ & Weed management & 234 & 97.50 \\
\hline $\mathbf{1 0 .}$ & Thinning & 182 & 75.80 \\
\hline $\mathbf{1 1 .}$ & Irrigation management & 6 & 2.50 \\
\hline $\mathbf{1 2 .}$ & Harvesting & 238 & 99.20 \\
\hline
\end{tabular}

*Multiple responses obtained

Three-fourth of the respondents were found to get adopt the recommended thinning practices.

Very meagre $(2.50 \%)$ level of the respondents had adopted the irrigation management practices. Around 99.20 per cent of the respondents had adopted the harvesting practices at the recommended time period.

\section{Acknowledgements}

We thank Dr. P. Balasubramaniam, Professor and Head of the Department of Agricultural Extension and Rural Sociology, Tamil Nadu Agricultural University, Coimbatore for his guidance and constant help throughout the research work, Dr. R. Arunachalam, Professor and PG Coordinator, Department of
Agricultural Extension and Rural Sociology, Tamil Nadu Agricultural University, Coimbatore for laudable counselling and surpassing guidance throughout the study. i am very thankful to Mr. Anbarasu and Mr. MariaJoseph, Assistant Agricultural Officers, Jawadhu hill who given the timely help and provided the details necessary for my research work. Finally I thank UGC council who provided financial assistance throughout the period of my research study taken in the hilly area.

\section{References}

DHAN foundation, Report of Supporting millets in India: Policy Review and Suggestions for Action, 2012, can be 
retrieved from http://www.dhan.org/smallmillets/ docs/report/Millet_Support_Policies.p df

Directorate of millets Development, Govt. of India, 2010. http://dmd.dacnet.nic.in/

http://www.srtt.org/institutional_grants/rural_ livelihoods_communities/rgr_upscalin g\%20popularisation\%20of\%20little\% 20millet.html

Vasanthapriya, S. 2015. Socio-economic impact of little millet (Samai) cultivation among tribal farmers. Unpub. M.Sc. (Ag) Thesis, TNAU, Coimbatore.

www.fao.org/

\section{How to cite this article:}

Vasanthapriya, S. and Asokhan, M. 2019. Study on Adoption of Recommended Cultivation Practices in Little Millet (Panicum millare) among Hilly Tribe Farmers in Jawadhu Hills of Tiruvannamalai District, India. Int.J.Curr.Microbiol.App.Sci. 8(10): 890-894. doi: https://doi.org/10.20546/ijcmas.2019.810.103 